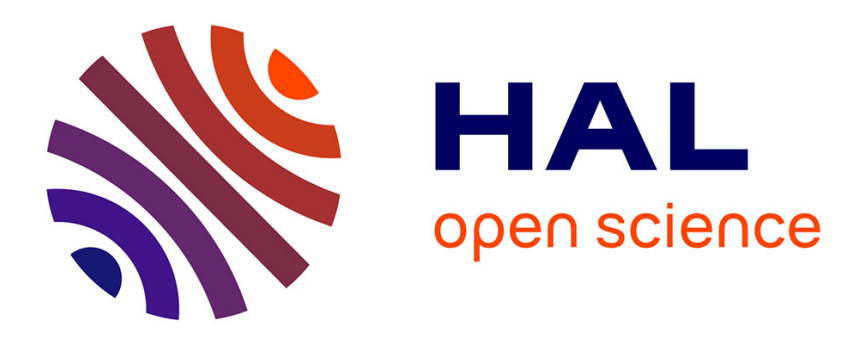

\title{
Description versus rejection in the analysis of negation: Evidence from Romanian and English
}

\author{
Elena Albu
}

\section{To cite this version:}

Elena Albu. Description versus rejection in the analysis of negation: Evidence from Romanian and English. Lingua, 2017, 191-192, pp.22-41. 10.1016/j.lingua.2017.02.001 . halshs-02912949

\section{HAL Id: halshs-02912949 \\ https://shs.hal.science/halshs-02912949}

Submitted on 7 Aug 2020

HAL is a multi-disciplinary open access archive for the deposit and dissemination of scientific research documents, whether they are published or not. The documents may come from teaching and research institutions in France or abroad, or from public or private research centers.
L'archive ouverte pluridisciplinaire HAL, est destinée au dépôt et à la diffusion de documents scientifiques de niveau recherche, publiés ou non, émanant des établissements d'enseignement et de recherche français ou étrangers, des laboratoires publics ou privés. 


\title{
Description versus rejection in the analysis of negation: Evidence from Romanian and English
}

\author{
Elena Albu \\ University of Geneva, Department of Linguistics, Switzerland
}

Received 18 July 2015; received in revised form 7 February 2017; accepted 17 February 2017

Available online 14 April 2017

\begin{abstract}
Found at the interface between cognition, language and logic, this paper discusses the mental representation of negation in natural language. Following the framework provided by Relevance Theory, it suggests that different types of negation represent actualizations of either the descriptive or the metarepresentational use. An account of descriptive negation and metarepresentational negation is offered based on the logical, semantic and pragmatic relations between the negative utterance and its formal affirmative correspondent, on the one hand, and semantic affirmative correspondent, on the other. Metarepresentational negation is defined as the rejection of a formal affirmative correspondent, always an instance of a second-order interpretation while descriptive negation represents the assertion of a negative content in the form of a semantic affirmative correspondent, always an instance of a first-order interpretation. This investigation is supported by a large corpus analysis represented by authentic Romanian and English data.

(c) 2017 Elsevier B.V. All rights reserved.
\end{abstract}

Keywords: Metarepresentation; Descriptive negation; Metarepresentational negation; Metalinguistic negation; Affirmative correspondents; Singular square of opposition; Relevance theory

\section{Introduction}

Characterised by multi-functionality, negation is associated with different interpretations: as a logical connective, it has a wide scope, reversing the truth value of a proposition $p$ in $p$ (Horn and Wansing, 2015), at the linguistic level, it represents a narrow scope constituent negation (Moeschler, 2013), while its processing is said to be non-incremental, involving a two-step interpretation (Kaup et al., 2007) and activating different regions in the brain (Tettamanti et al., 2008). That it is not a homogeneous phenomenon is also indicated by the variety of negative utterances that contribute differently to meaning identification and interpretation. For instance, a negative utterance can be used alone or can be followed by a follow-up clause and the relation between negation and its positive follow-up can be of downward or upward nature, as illustrated by the following examples:

(1) $\mathrm{He}$ is not the president of the party anymore.

(2) I have not promoted him.

(3) She is not beautiful; she is gorgeous.

(4) She is not beautiful but ugly.

(5) She is not driving but walking.

E-mail address: elena_albu84@yahoo.com. 
The mental operations triggered when computing these negative utterances and their constitutive elements as well as the argumentative impact they have on the hearers' cognitive environment play an important role in the correct interpretation of the negative utterances. Following the research initiated in Albu (2012a,b), the aim of this paper is to discuss the mental structure and interpretation of such negative utterances in natural language. The claim is that these negative utterances can be accounted for in terms of the dichotomy between 'descriptive and interpretive use' developed in Relevance Theory (Sperber and Wilson, 1995) and complemented by studies on the phenomenon of metarepresentation (Sperber, 2000; Wilson, 2000). In light of these criteria, the cognitive and communicative behaviour of descriptive negation (DN) and metarepresentational negation (MetNeg) will be discussed. This study is based on the premise that DN and MetNeg represent two distinct negative types that have predetermined mental structures, i.e. they are the output of particular cognitive mechanisms. On the contrary, despite their predetermined mental structure, they can have multiple context-dependent roles and functions in accordance with the speaker's communicative goals.

A metarepresentation-based approach will set clear criteria of delimitation between DN and MetNeg in terms of what inferences are triggered and what cognitive effects are yielded. The theoretical proposal is supported by a large corpus analysis provided by authentic Romanian ${ }^{1}$ and $E_{n g l i s h}{ }^{2}$ political discourses. The prototypical way of negating the sentence in Romanian is by means of a negative morpheme in pre-verbal position, i.e. nu (Eng. not) while in English negation is formed by adding the free-standing adverb not or the bound inflectional form n't after an auxiliary verb. Although Romanian and English display different structural properties, the comparative perspective on two different languages attempts to indicate which features are stable cross-linguistically and which features are language specific. The contextual approach will highlight the elements that triggered negation in the first place and emphasize its constitutive elements in order to offer a more comprehensive explanation of how the interpretation of negation is reached in natural language.

For the purposes of the argument, I shall proceed as follows. In section 2 a brief overview on previous accounts on negation will be offered, with an emphasis on the dichotomy between descriptive and metalinguistic negation. In the next section, the theoretical framework used is discussed, the focus being on the distinction between the descriptive and interpretive use. Based on the singular square of opposition and on the contextual data analysis, in section 4 the logical, semantic and pragmatic properties of the two possible positive correspondents of a negative utterance: the formal affirmative correspondent and the semantic affirmative correspondent are presented. In section 5 I elaborate on two working hypotheses, according to which DN is the actualization of the descriptive use and MetNeg is the actualization of the metarepresentational use and claim that the activation and rejection of a formal affirmative correspondent represents an essential condition for MetNeg. In contrast, DN represents the assertion of a negative content, always a first-order interpretation. Conclusions will be drawn in the last section.

\section{Previous accounts on negation}

There are different classifications of negation based on various criteria suggested in the literature. Russel (1905) distinguishes between external vs. internal negation. External negation is said to have in its scope a full logical proposition, containing no free variables, while internal negation takes in its scope a propositional function, i.e. a nonpropositional form containing free variables (cf. Moeschler, 2010). Jespersen (1917) suggests nexal vs. special negation defined in terms of position of negative morpheme. Nexal negation is the negation of the proposition corresponding to the given nexus, which is defined as "a combination of a predicate element with the arguments that it is predicated of" (cf. McCawley, 1995). Special negation includes: 'incorporated negatives', contrastive negation and the negation in derived words, such as unhappy, impossible, disorder. Klima (1964) differentiates between sentential vs. constituent negation, i.e. negation taking action on the sentence as a whole vs. on a constituent, respectively. This syntactic classification has more semantic correlations. First, it can correspond to the distinction between wide vs. narrow-scope, i.e. taking scope over the entire sentence or over a constituent. Second, syntactic sentential negation is said to semantically express a contradictory proposition while constituent negation gives a contrary proposition (cf. Borschev et al., 2005).

Another illustration of the multiple interpretations negation can have is represented by the dichotomy between 'descriptive negation' (DN) and 'metalinguistic negation' (MN) (Carston, 1996, 1999; Ducrot, 1972, 1984; Horn, 1985, 1989/2001; Moeschler, 1993, 1997, 2010, 2013, to name but a few). Distinct views were advocated, some of them defending the view that the distinction between $\mathrm{DN}$ and $\mathrm{MN}$ is rather a distinction between a truth conditional operator vs. a metalinguistic one (Horn, 1985, 1989). In contrast, there are views according to which there is no ambiguity at the level of the negative operator and the different uses of negation are the consequence of the humans' cognitive ability for metarepresentation (Carston, 1996, 1999; Noh, 2000).

\footnotetext{
${ }^{1}$ The Romanian corpus of data is collected from the websites of different politicians and political parties: http://www.psd.ro/transcripte.php and http://www.crinantonescu.ro/Public/cat/14/Noutati.html.

2 The English data are collected from the UK Parliament website.
} 
Descriptive negation is broadly interpreted as the standard truth-functional negation, i.e. affecting the truth conditions of a sentence. The label of 'descriptive negation' is first mentioned by Ducrot (1972) who considers it a delocutive derivation of 'polemic negation', one that objects to views put forward by other speakers. From that discursive perspective, negation is always the marker of a disagreement and cannot be equated to a logical operator. In contrast, Horn (1985, 1989/2001) asserts the truth-conditional role of descriptive negation that separates it from metalinguistic negation without a truth-value contribution. This means that there are more negative operations, one of which is not dependent on logical relations. A third interpretation argues that metarepresentation characterizes the metalinguistic but not the descriptive variety (Carston, 2002; Noh, 2000). Negation is always truth-functional but the truth function does not refer to the same type of representation.

As opposed to the descriptive truth-functional negation that operates over a proposition, metalinguistic negation is thought to involve an extended use of negation as a way for speakers to announce their unwillingness to assert something or to accept a certain assertion. It is said to be a special non-truth-functional use of the negation operator, which can be glossed as I object to $U$ where $U$ is a linguistic utterance (Horn, 1985). Among the properties that can be objected to, the following have been mentioned in the literature: the pronunciation of a word, the insufficient strength of a lexical item used, a non-truth-conditional aspect of the semantics of a word, the stereotypic assumptions or connotations that come with a particular word or phrase, an existential 'presupposition' carried by a sentence/utterance in (Carston, 1996:309). Regarding its properties, $\mathrm{MN}$ is said to occur in rejoinders to utterances of the corresponding affirmative, to constitute a logical contradiction, to represent garden-path utterances, to require double processing and to involve the 'contradiction' intonation contour (a final rise within the negative clause), followed by a correction clause, and contrastive stress on the offending item and its replacement (cf. Carston, 1996:311-12). However, it is claimed that not all instances of MN are rejoinders of the corresponding affirmative as the follow-up clause can be placed on the first position, and that they do not always represent garden-path utterances. In contrast, it is said that "the material in the scope of the negation operator, or some of it at least, is echoically ${ }^{3}$ used" (Carston, 1996:320), i.e. it reports what someone else has said or thought and expresses an attitude to it". In opposition to Horn's account, which includes only the cases of resemblance in form, the author claims that the target of the echo can be represented by both semantic or conceptual content as well as by the set of linguistic factors represented by phonetic, grammatical or lexical properties, aspects of dialect, register or style, and paralinguistic features such as tone of voice, pitch or other gestures, audible or visible (Carston, 1996).

In spite of the tendency to interpret negation globally, in language use negation is usually associated with the VP but the meaning is that of constituent negation having a narrow-scope and a contrary interpretation. Additionally, the dichotomy between DN and MN does not seem to account either for the mental structure and the interpretation process of all the examples in (1-5). In the present paper the cognitive criteria responsible for how negation is mentally structured and interpreted will be under investigation. The underlying hypothesis is that DN is always the actualisation of the descriptive use while $\mathrm{MN}$ is rather a subtype of a bigger class of negative utterances represented by MetNeg. If previous studies have looked at complex negative utterance, i.e. [negation + correction], this approach will also account for the situations in which negation consists in only one clause, as indicated in examples (1) and (2). To this end, particular attention will be paid to the logical, semantic and pragmatic properties of DN and MetNeg, in light of their main components, such as the formal and the semantic affirmative correspondent, and of the relations between them.

\section{Relevance theory: prefatory remarks}

The general claim Relevance Theory (Sperber and Wilson, 1995; Wilson and Sperber, 2002) makes is that human communication is overtly intentional, i.e. the speaker always has an intentional communicative behaviour which is inferred by the audience. 'Relevance' is considered to be the property of the stimuli, which creates expectations that are precise enough and predictable enough to guide the hearer towards the speaker's meaning. An input is relevant to an individual when the processing in a context of available assumptions yields positive 'cognitive effects', defined as: worthwhile differences to the individual's representation of the world, resulted from the interaction between new and old information in a given context (Wilson and Sperber, 2002). Three types of cognitive effects have been identified, as follows: 'strengthening of the existing assumptions', 'contradiction and elimination of the existing assumptions' and 'derivation of a contextual implication' which takes place when the input combines with contextual assumptions to yield implications that follow from the context and input together (Sperber and Wilson, 1995; Wilson and Sperber, 2002).

According to Relevance Theory, a representation can be used in two ways: either descriptively, representing some state of affairs in virtue of its propositional form being true of that state of affairs, or interpretively, representing some other representation, which also has a propositional form (Sperber and Wilson, 1995:232). The authors claim that "every

\footnotetext{
3 'Echo' as defined in Wilson and Sperber $(1988,1992)$.
} 
utterance is the interpretive expression of the speaker's thought" (Sperber and Wilson, 1995:231) which means that there is always a relation of resemblance between the propositional form of the utterance and the propositional form of the speaker's thought (Sperber and Wilson, 1995:228). It follows that the descriptive use and the interpretive use can be referred to as the interpretation of a description and the interpretation of an interpretation, respectively.

The interpretation of a description is characterised by an interpretive relation based on resemblance between the propositional form of the utterance and the speaker's mental representation while the relation between the speaker's thought and the state of affairs is based on truth-conditions. The interpretation of a description always determines a firstorder interpretation, i.e. the propositional form of the utterance is an interpretation of the speaker's thought which is always entertained as a description of a state of affairs. Illustrating the speaker's perception on the given state of affairs, the resulted representation is self-attributed, i.e. there are no other discursive entities and no other discursive levels involved.

In the case of the interpretation of an interpretation, a representation can also be used to represent another representation, such as a different utterance, a thought or an abstract linguistic entity. Unlike the descriptive use, the interpretive use always involves a second-order interpretation. Recent developments in cognitive science treat the interpretive use in light of the phenomenon of 'metarepresentation' defined as follows: "a higher order representation with a lower order representation embedded in it" (Wilson, 2000:411). The higher-order representation (HOR) is generally represented by 'utterances' (public representations) or 'thoughts' (mental representations). There are three main types of lower-order representation (LOR): 'utterances' (public representations), 'thoughts' (mental representations) and 'sentences, propositions' (abstract representations) (Wilson, 2000:414). Sperber discusses the properties of each of the three types of LOR, indicating that the abstract representations are reduced to their logical, semantic and epistemic properties, which means that they may be true or false, standing in relations of entailment, of contradiction, of warrant, of being a good argument one for the other, of meaning similarity (Sperber, 2000:127). Mental and public representations have the same content properties as their abstract counterparts. Mental representations are linked to an individual and can be normatively evaluated in psychological terms, while public representations typically occur in the communicative environment of two or more people and have a certain linguistic form and a certain content in a certain context (Sperber, 2000:128). The following example, adapted from Sperber (2000:127), illustrates the metarepresentational use, in the form of a mental representation of a public representation:

\section{(6) Peter thinks that Mary said that pigs fly.}

There are linguistic markers pointing to the mental and public nature of the representations: the verb to think and the verb to say, respectively. The content of this metarepresentation is represented by the state of affairs pigs fly. In other words, HOR is represented by Peter's thought while LOR by Mary's utterance whose content is pigs fly: \{Peter thinks that [Mary said that (pigs fly)]\}. The relation between the propositional form of Peter's thought and Mary's utterance is one of resemblance, i.e. they share logical properties and have identical contextual implications in the given context. A second relation of resemblance is also found at the level of the LOR between the propositional form of Mary utterance and the propositional form of Mary's thought. In sum, the interpretation of an interpretation involves more representations, mental, public or abstract, situated on different discursive levels, uttered or thought by distinct discursive entities and characterised by different relations.

The metarepresentational use is said to have two main subtypes: 'interpretive use' and 'metalinguistic use' (Noh, 2000). The interpretive use involves a second-order interpretation where the speaker's thought is itself used to metarepresent another thought or utterance which it resembles in content. Metalinguistic use involves a second-order interpretation where the speaker's thought is itself used to metarepresent another thought or utterance which it resembles in linguistic form (Noh, 2000:75). It results that the metarepresentational use is divided in two main subcategories: the first one is represented by the 'metarepresentational conceptual' use while the second by the 'metarepresentational metalinguistic' use.

The metarepresentational ability plays an important role in the communicative activity. ${ }^{4}$ Starting with Grice (1989), the speaker's meaning is considered to involve different layers of metarepresentation, being doubly embedded, i.e. the speaker's goal is to make the informative intention mutually manifest, and the process of understanding implies the inference of a mental state of the speaker. In order to interpret the speaker's meaning, the hearer must enrich the decoded sentence meaning at the explicit level and complement it at the implicit level by supplying contextual assumptions which will combine with it to yield enough conclusions to make the utterance relevant in the expected way (Wilson and Sperber, 2002:258-259). Therefore, there is always a distinction to be made between the metarepresentational complexity of human communication in general versus the metarepresentational complexity of language itself.

\footnotetext{
${ }^{4}$ There is a dichotomy between 'metarepresentation' vs. 'theory of mind': the latter deals with the ability to form thoughts about attributed thoughts while metarepresentation is more complex, encompassing another two more types of abilities: metacommunicative and metalogical.
} 
In sum, there are two main ways of using a representation: either descriptively or metarepresentationally, in the sense of metarepresentational complexity of language itself. Taking into account their properties, the descriptive and metarepresentational use appear to be mutually exclusive, i.e. an utterance can be the actualization of either one or the other.

\section{Formal affirmative correspondent vs. semantic affirmative correspondent}

\subsection{FAC, SAC and the logical square of opposition}

Starting from Ducrot's (1972:37) example in (7a), two affirmative correspondents, a 'formal' one, where the negative operator has been removed, and a 'semantic' one, similar in meaning with the initial negative utterance (NEG) in (7), can be identified, as follows:

(7) a. II n'y a aucun nuage au ciel.

b. There are no clouds in the sky.// There are not any clouds in the sky.

(8) a. Il y a des nuages au ciel. (French)

b. The are clouds in the sky.

(9) a. Le ciel est pur. (French)

b. The sky is clear.

Comparing the two possible positive correspondents, the 'formal affirmative correspondent' (FAC) in (8) and the 'semantic affirmative correspondent' (SAC) in (9), it can noticed that they cannot be interchanged without altering the meaning and, more importantly, they seem to be activated in different contexts. In terms of logical relations between the three types of sentences, FAC, SAC, NEG, the following can be noticed based on the singular square of opposition Horn suggests (2014):

i. there is a contradictory relation between the FAC in (8) and the NEG in (7), i.e. the truth of one implies the falsity of the other and conversely,

ii. the SAC in (9) entails NEG, i.e. SAC entails NEG if and only if whenever SAC is true, NEG is true too. Also, the FAC in (8) entails the non-SAC the sky is not clear.

iii. the relation between FAC and SAC is one of contrariety: they cannot be both true but they can be both false.

iv. the relation between non-SAC and NEG is one of sub-contrariety: they cannot be both false but they can be both true.

These logical relations are illustrated in Fig. 1.

In order to offer a comprehensive explanation of the mental structure and interpretation of DN and MetNeg, particular attention will be paid to the interplay between their logical, semantic and pragmatic features. The logical relations illustrated by the logical square of opposition represent the logical form of a conceptual representation, i.e. "a well-formed formula, a structured set of constituents, which undergoes formal logical operations determined by its structure" (Sperber and Wilson, 1995:72). Accordingly, the logical relations displayed by the logical square are part of the logical form of the

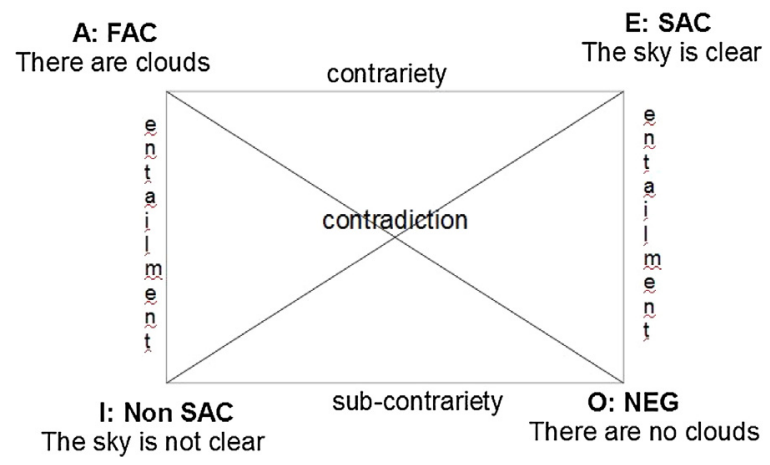

Fig. 1. The logical relations displayed in the singular square of opposition. 
conceptual representation. The logical form is completed into the fully propositional form by the hearer and can be entertained in different ways in further inferences: I believe that $P, I$ desire that $P$.

The claim is that DN and MetNeg have different mental structures, being the outputs of different cognitive mechanisms which yield distinct cognitive effects. Furthermore, DN and MetNeg appear in distinct contexts which display particular features. In what follows, I will indicate in which contexts and under what circumstances these two positive counterparts are activated and what roles they play in the interpretation of the negative structure.

If we take a look at the negative clauses in the examples discussed in the Introduction section, the following FACs can be identified: he is the president of the party; I have promoted him; she is beautiful; she is beautiful and she is driving, respectively. In contrast, identifying the SACs does not seem to be an easy task nor always possible: at first sight, the SAC for not to be president could be represented by to have a different function or no function at all, for not to promote somebody by to obstruct, to discourage someone (i.e. to do the opposite of promoting), for not to be beautiful in both (3) and (4) by to be ugly and for not to drive again many options seem to be available. The identification of SACs appears to be less complex only when prototypical contrary predicates are available, as indicated in (3) and (4). The use of the positive follow-up clause plays a role in indicating which SAC the speaker intended to use, as illustrated for instance in example (5), where to walk is pointed out as the intended SAC. The situation is not clear as regards example (3) because to be gorgeous does not appear to be the intended SAC, as previously predicted. Therefore, a difference is to be made between a SAC and the affirmative follow-up clause: even if they may sometimes coincide, they are actualised differently and play distinct roles in the process of meaning computation and interpretation.

Looking at the variety of SACs, their activation seems to depend on more factors, such as: the nature of the entities used which leads to different types of polar opposition, their scalar vs. non-scalar character, the lexical aspect of the phrases involved. Furthermore, the activation of SACs appears to have a strong contextual character which creates an asymmetry with respect to the logical relation between NEG and SAC, as the entailment between SAC and NEG exists between any two entities that are put in relation contextually.

In order to explain how only one SAC is selected and activated in a particular context, let's take a look at the semantics of the negative utterances in (1) and (2), where negation is used alone. Not to be the president and not to promote someone raise two issues. First, they have large denotations, i.e. more options are available as previously indicated, which makes them representationally ambiguous. Second, only a follow-up clause could help specify the actual scope of negation, i.e. where the negation actually takes action. Without any explicit positive segment, negation can target different elements, as indicated by the following formulas in (a) and (b). The first one corresponds to a wide scope reading of negation, whose meaning is that there is not such an $x$ with the propositional function $B(X)$, while the second one represents an internal negation (i.e. a narrow scope reading of negation) which takes action on the propositional function $B(X)$ :
(a) $\neg \exists \mathrm{xB}(\mathrm{x})$
(b) $\exists x \neg B(x)$

But if we place these examples in their original context, as in (10) and (11), the ambiguity seems to be solved and these negative utterance do not pose problems of interpretation for the interlocutors anymore. The intended reading is the one pointed out in (b) $\exists \mathrm{x} \neg \mathrm{B}(\mathrm{x})$ :

(10) Mihai Gâdea: Dacă vi s-ar propune o astfel de situație, situație pe care și dumneavoastră pe vremea când nu erați președintele PSD și negociați pentru susținerea dumneavoastră, i-ați propus-o lui Cristian Diaconescu, ați susține-o? Da sau nu.

nu erați președinte-le PSD

not were 2SG president-art.def. PSD

'Mihai Gâdea: If this kind of situation were proposed to you, situation which you had proposed to Cristian Diaconescu, when you were not the president of PSD and were negotiating for your support, would you endorse it? Yes or no.'

(11) Reporter: L-ați sfătui să candideze și la președinție în următoarele alegeri? Traian Băsescu: Nu. Pentru președinția României... Poate la oamenii de gen Baconschi, poate Preda. Baconschi este un intelectual bine definit. Nu I-am creat eu.

$\mathrm{Nu}$ I- am creat eu.

Not clitic 3SG created 1SG I 


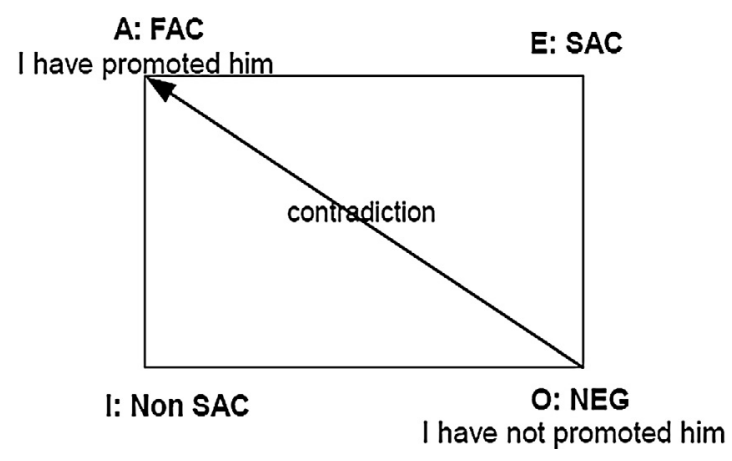

Fig. 2. The interpretation process for $\operatorname{MetNeg}[\operatorname{Not}(X)]$.

'Reporter: Would you advise him to run for president in the next elections? Traian Băsescu: No, for Romania's presidency ... maybe people like Baconski, maybe Preda. Baconski is a well-defined intellectual. I have not promoted him.'

In (11) it appears that the accent is not placed on the positive alternative but rather on the fact that it is not the case to consider that the speaker was the one to have promoted the mentioned politician (despite the fact that the mentioned politician was promoted or not). The rejection targets the assumption according to which the main speaker, as indicated by the personal pronoun $I$, was the person to carry out the action of promoting the mentioned politician. The speaker does not want to convey an alternative but to reject some background assumptions he attributes to his interlocutor. Therefore, the hearer completes the logical form $I_{i}$ promoted him $_{i}$ into a full-fledged propositional form: I believe that $I_{i}$ promoted him $_{i}$, which in turn the speaker embeds it into a second-order representation I believe that you believe that I have promoted him. It results that only the FAC $\left(I_{i}^{5}\right.$ promoted $\left.h_{i m}\right)$ plays an active role in the computation of this negative structure, as indicated in Fig. 2. The sense of the arrow indicates how the interpretation is reached in the case of a simple NEG:

In other words, in the interpretation of the negative clause the hearer goes through the FAC, which can be available in the context or can be activated by means of NEG, as in the present situation, qualified as false, given the contradictory relation between FAC and NEG. ${ }^{6}$ In sum, the negative structure creates a particular context of interpretation, which can be glossed as [NOT $(X)$ ], where $(X)$ is derived from the positive representation and points out the representation at the discourse level. The glossing formula corresponds in this case to: [NOT (I promoted him)]. This means that the configuration of negation in (11) is metarepresentational, the FAC being the equivalent of LOR, while NEG is the equivalent of HOR.

Being presented out of context, (1) is also ambiguous between the activation of a FAC as shown in (12) or of a SAC as in (13):

(12) $\mathrm{He}$ is the president of the party.

(13) a. He had a different position.

b. He retired.

If the FAC he is the president of the party were activated, it would mean that the negative operator takes action on this representation, as indicated by the glossing formula: [NOT (he is the president)]. If this is the case, the FAC and (X) cannot be placed on the same level, i.e. it cannot represent a descriptive representation, but it would be a case of metarepresentation, i.e. the representation of a representation. Regarding the activation of SACs, more options come to mind when the negative utterance is out of context, as shown in (19a-b). Embedded in its initial context, the situation in (1) in comparison with the one in (2) appears to be different: the FAC he is the president of the party does not seem to play an active role. Instead, the SAC in (13a) he had a different position is available in the given context, as there is no indication according to which he was not part of that party at that particular moment.

\footnotetext{
${ }^{5}$ For reasons of consistency, the logical form you promoted him will be expressed from the speaker's point of view as $l_{i}$ promoted him ${ }_{i}$ in lexical semantics, where $l_{i}$ refers to the speaker from the hearer's perspective.

${ }^{6}$ To avoid any confusion, FAC is always available and in a contradictory relation with the negative utterance, but given the type of the mental structure, it can or can't be used in the computation of the negative utterance.
} 
If we take a look at the following examples extracted from the British Parliament, the following FACs can be identified: for (14) those who maintain certain standards, for (15) I am a member of the NSS, for (16) I am arguing that there should or must be prayers before a council meeting followed by I am arguing that the prayers must be of a Judaeo-Christian nature.

(14) The Bill puts in place a recall mechanism for MPs which is transparent, robust and fair. It strikes a fair balance between holding to account those who do not maintain certain standards of conduct, while giving MPs the freedom to do their job and make difficult decisions where necessary.

(15) So the National Secular Society, which I would like to thank for drawing some of these issues to my attention-I am not a member of the NSS and I doubt I ever will be-has a point when it says: "The absence of prayers from the formal business of local authority meetings does not impede the religious freedoms of believers or deny anybody the right to pray."

(16) Sir Edward Leigh: I drafted my new clause carefully. It is meant to constitute a serious contribution to the debate. I am not arguing that there should, or must, be prayers before a council meeting. Of course, no one needs to go to them anyway. It is simply a decision that is made at the time of the council meeting. Nor am I arguing that the prayers must be of a Judaeo-Christian nature. I am, however, making the serious point, in this House of Commons, that this is our past. This is our foundation. This is what has made us free.

Regarding the SACs, for (14) one possibility would be those who disobey certain standards of conduct and for (15) I am a member of a different organisation or I am not a member of any organisation. In (16), given the complexity of the negative utterance, a SAC does not seem to be available at first sight.

The context in which these examples are used play an important role, as the activation of either a FAC or of a SAC becomes unambiguous. For instance in (14) the FAC does not seem to play any role in the mental structure of the negative utterance, i.e. there is no representation level involved, FAC is only part of the logical properties which are not used in this situation. In contrast, in (15) the FAC is activated and rejected as false, which leads to a structure with the following glossing formula: [NOT (I am the member of the NSS)]. The same situation seems to occur in (16). Although the example is more complex given its discursive structure, the identification of the corresponding FACs is possible. The negative segment consists in two parts, connected by means of nor which indicates the existence of two FACs: [NOT (I am arguing that there should or must be prayers before a council meeting)] and [NOT (I am arguing that the prayers must be of a Judaeo-Christian nature)], respectively. Moreover, the opposition is created in relation to the follow-up corrective segment that contributes to the delimitation of the scope of negation. To put it differently, the positive follow-up clause in these two examples represent the intended SAC. The following figure indicates how the interpretation of these two MetNeg [Not (X) but $\left.\left(X^{\prime}\right)\right]$ is achieved. The glossing formula emphasizes the mental structures of a NEG represented by [Not (X)] followed by a corrective follow-up represented by [but ( $\left.X^{\prime}\right)$ ]. Looking at Fig. 3, the first arrow (from NEG to FAC) indicates the step represented by the activation and rejection of FAC as false and the second arrow (from FAC to SAC) indicates in the second step when the interpretation reaches the SAC as the alternative to the rejected representation:

On balance, there is a strong connection between the activation of a FAC and the computation of MetNeg: the FAC represents the basis for the action of rejection, which always leads to a second-order interpretation. This conclusion is also supported by the possibility of inserting a meta-comment or an explanatory remark in order to indicate the presence of multiple representations and discursive entities. For instance, in (11), although there is no explicit marker to indicate more

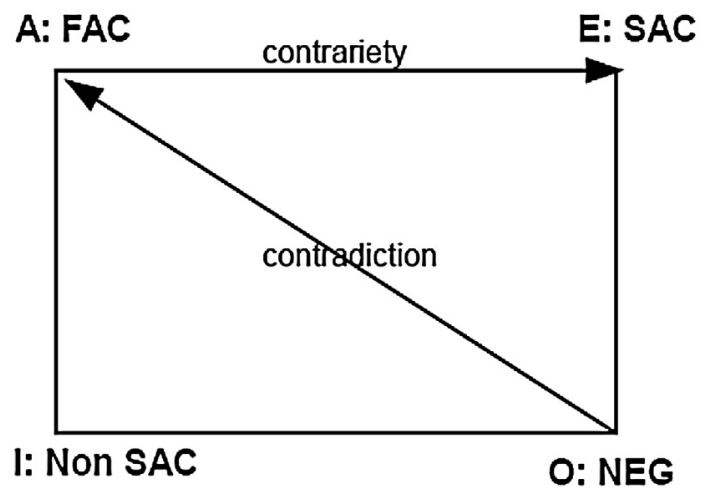

Fig. 3. The interpretation process for MetNeg followed by correction. 
representations, a comment like: as you may think it, or embedding the structure into a conditional type of reasoning, like: if you believe that I have promoted him, it is not the case/true, would elucidate not only the presence but also the nature, i.e. a mental representation, of the rejected representation.

In summary, as regards a negative utterance, two positive counterparts are available: a formal one and a semantic one. Based on the logical relations between the FAC, SAC and NEG indicated by the singular square of opposition and by the contextual analysis of the data available, it results that SAC and FAC behave differently, being activated in either a descriptive context or a metarepresentational one. The following options are available:

i. one SAC is available out of more possible options in a particular context,

ii. either a FAC or a SAC is used in the computation of the negative utterance,

iii. if a FAC is activated, a SAC can be pointed out in a second step in the interpretation process.

\subsection{NEG and SAC}

The previous section shows that FAC and SAC are mutually exclusive, the activation of either one or the other playing an important role in the interpretation of a negative utterance. If FAC is directly related to the phenomenon of metarepresentation, i.e. the action of rejection associated with it implies the existence of multiple representations, in this section particular attention will be paid to the interplay between negation and SAC.

Concerning the activation of SAC, it is rather underspecified and open to interpretation when it is used out of context. Used in context, only a particular SAC seems to be selected, leading the interpretation towards the intended one. A further investigation of the logical, semantic and pragmatic relations between the negative utterance and its SAC would elucidate how the SAC is activated, selected and used in connection with a particular negative utterance. A logical analysis would indicate what type of relation exists between them, while a pragmatic perspective would highlight under what circumstances they are interchangeable or used in the same context. Moreover, a semantic perspective, would indicate to what extent they are symmetrical, i.e. they express the same meaning, aspect which will not be pursued in this paper.

Looking the example (1) He is not the president anymore, more SACs are available, each of them pointing towards different lines of interpretations. As a result, without the affirmative follow-up segment, the meaning of negation is underspecified. Given the large denotation, the politician can have a different position or no position at all, as shown in $(17 a-e)$ :

(17) a. He retired.

b. He has a different position.

c. He is the vice-president of the party now.

d. He died.

e. He was sent to prison.

From a logical perspective, according to the square of opposition, he's the president entails he did not retire and he retired entails he's not the president, but not the other way round. It results that SAC always entails NEG, while the relation between FAC and SAC is one of contrariety and between FAC and NEG one of contradictoriness. In other words, any option from (17a-e) is in a relation of entailment with the negation in (1), as indicated in Fig. 4:

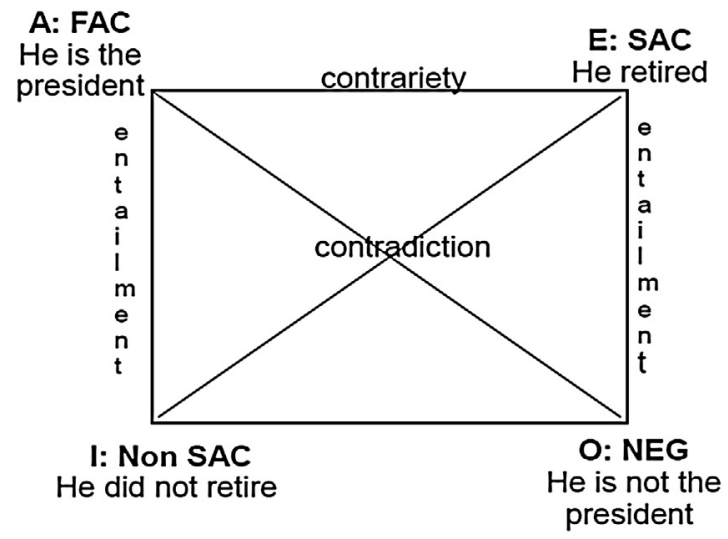

Fig. 4. The logical relations between the NEG "He is not the president" and its correspondents. 
Regarding the pragmatic relation between the SAC and NEG, there are three possibilities:

i. a SAC is activated and selected in a particular context

ii. the SAC replaces NEG

iii. the SAC is used in the same context together with NEG.

Each of these three situations raises different questions. For instance, why is only one SAC selected and activated out of many options in a particular context? Can SAC replace NEG? If so, at what cost? And under what circumstances do NEG and SAC appear together in the same utterance? Among the three cases, the third option will be pursued in this paper, while the first and the second will be approached in a future paper.

To test the pragmatic relations between the negative utterance and the SAC, I have created three possible contexts where the negation could be used together with the SAC, in contrast with the FAC, which cannot be used in the same statement. The first context is represented by a dialogue between $A$ and $B$, where $A$ is genuinely seeking for information:

(18) A: What is new with Peter?

$\mathrm{B}$ : He is not the president of the party anymore; he retired.

In this context, A is seeking for information and B's reply consists in a negative and in an affirmative segment. Both segments have the same argumentative line pointing to the new situation of Peter. The affirmative segment conveys a new piece of information that is added to the interlocutor's cognitive environment. Regarding the negative segment, given the discursive context, it has a different motivation. The negative statement implies that there are some shared background assumptions between $A$ and $B$, i.e. they both knew that Peter was the president of the party in the past. Furthermore, $A$ is aware of the new situation and he assumes that $B$ has not been updated about it and, therefore, he decides to share it with $A$. It results that the first segment represents the rejection of a mutually manifest assumption while the second one conveys the new item of information A initially asked for.

Two questions come immediately to mind: Why has B used both segments and not only the affirmative one? And second: what happens if the order of the negative and positive segments is reversed as in $\left(18 \mathrm{~B}^{\prime}\right)$ ?

(18) $B^{\prime}$ : He retired, he is not the president of the party anymore.

To answer the first question, the segments definitely communicate more information together and make the interpretation easier for B. If the assumption according to which Peter was the president of the party in the past indicated by the use of the adverbial phrase anymore and shared by $A$ and $B$ had not been explicitly rejected, $B$ would have had to infer it with some extra cognitive cost. The answer to the second question is found at the level of information structure which points directly to the speaker's communicative intention. In this situation, the negation would be the consequence of the fact that he retired, which still activates the background assumption according to which Peter was the president of the party in the past.

In the second context, A's statement represents a strong assertion:

(19) A: Peter is the president of the party.

$\mathrm{B}$ : Peter is not the president of the party (anymore); he retired.

It is still a case of rejection, but in comparison with the previous situation, a public representation explicitly uttered, i.e. a previous utterance, is rejected. The discursive function of the B' reply, i.e. [NEG + SAC] is corrective. The use of the adverbial phrase anymore is optional in this situation. Moreover, the negation is implicit and compulsory in contrast with the first context where the use of negative segment is optional.

In the third situation, A asks a 'yes-no' question:

(20) A: Is Peter the president of the party?

$\mathrm{B}$ : $\mathrm{He}$ is not the president of the party (anymore); he retired.

Looking at the dialogue in (20), a simplified version of it is:

$\left(20^{\prime}\right) \quad$ A: Is Peter the president of the party?

B: He retired. 
At a closer look, it can be noticed that negation is implicit, as follows: $B^{\prime}$ : No, he's not, he retired. The positive clause functions like a clarification of the 'no' reply.

In sum, the SAC in (17a) can accompany the negative clause in three distinct contexts that configure the information differently. It can also occupy the first position, with some differences at the level of information structure, or it can be the only option, but in this case negation is implicit. There are similarities between the interpretation process of the negative utterances in the first and second context. What these two situations have in common, is represented by the fact that negation functions metarepresentationally, i.e. it represents a rejection of either a background assumption or a public representation. In the first context, the SAC comes as the piece of information that is missing from the hearer's cognitive environment. In the second context, the positive segment brings new information into discussion, by rejecting and correcting a false representation of $A$. In other words, in all these two contexts the FAC is activated generating the action of rejection and the SAC is used in the same context with the negative utterance. In the third context, the SAC represents an answer to the question $A$ asked.

\subsection{SAC vs. the affirmative follow-up clause}

Metalinguistic negation is often discussed in correlation with the follow-up corrective clause. In the previous sections it was pointed out that there is no direct correspondence between the SAC and the affirmative follow-up; the next step is to see what similarities and what differences are between these two components. To this end, particular attention will be paid to the relation between NEG and SAC with an emphasis on which discursive markers can be used to describe the relation between them.

If we put together the negation in (1) with the available SACs in (17), we get the following combinations:

(21) a. He is not the president of the party anymore, he retired.

b. He is not the president of the party anymore, he has a different position.

c. He is not the president of the party anymore, he is the vice-president of the party.

d. He is not the president of the party anymore, he died.

e. He is not the president of the party anymore, he was sent to prison.

In order to identify the discourse relations between the clauses presented in (21) some offline experiments using linguistic judgement tasks ${ }^{7}$ with 14 native speakers of Romanian have been carried out. The participants were asked to choose between "corrective but" and "because" 8 to mark the discourse relation between the negative sentence and the affirmative one. They could opt for: "corrective but", "because" or both options. It appears that in (a), (d) and (e) the relation is marked by 'because': in (d) and (e) the subjects opted $100 \%$ for 'because' and in (a) $78.6 \%$ of them opted for 'because', $14.3 \%$ for 'corrective but' and $7.1 \%$ for both options. In (b) and (c) the relation may be represented by both 'corrective but' and 'because'. In (c) $78.6 \%$ of the participants opted for 'corrective but', $14.3 \%$ for both options and $7.1 \%$ for 'because', while in (b) $50 \%$ opted for 'corrective but', $35.7 \%$ for both options and $14.3 \%$ for 'because'.

If we apply the same test in (21) to the three alternative contexts in (18-20), the following can be noticed. In the first context, the 'because' relation does not apply, while in the second and third one, the interpretation is ambiguous between 'corrective but' and 'because' when the adverbial phrase anymore is used. If anymore is dropped, the reading with the 'corrective but' becomes unquestionable. Furthermore, in the third context, the reading without anymore would be the natural one.

All in all, SAC is interpreted as 'correction' when its relation with the negative segment is marked by 'corrective but' and as 'explanation', clarification when the relation is marked by 'because'. There is not always a clear-cut difference between the two uses. Some differences between the two readings can be found at the level of the constituents, as well: in (21b) and $(21 \mathrm{c})$ where 'corrective but' is preferred, the reading is directed towards having a position in comparison with (21a) and (21d) where having a position in the party is not the case anymore. In terms of similarities, both the corrective and the explanatory reading of SAC appear to be metarepresentational in nature.

In conclusion, SAC can be represented by different available contraries, displayed in various degrees of semantic similarity with the negative utterance. Even if both FACs and SACs can be identified, only one of them can actively contribute to the computation of the negative utterance. The situation seems to be simpler where there are two segments

\footnotetext{
${ }^{7}$ For the offline judgment tests the online survey has been used: https://freeonlinesurveys.com/app/dashboard.asp.

${ }^{8}$ Concerning the role of discourse markers, they are thought to facilitate the interpretation process, to guide it, but they are not responsible for it. Their selection is not compulsory, the difference they make is at the level of the processing effort.
} 
involved: [NEG + SAC], as the positive sentence specifies the scope of negation, guiding the interpretation either towards correction or explanation.

\section{Descriptive negation vs. metarepresentational negation}

\subsection{MetNeg}

Based on the differences between SAC and FAC, it appears that there are two ways in which information can be configured in the case of negation: (a.) when there is a FAC activated and plays an active role, and (b.) when it is not. The situation in (a) is an intrinsic case of metarepresentation, as the activation and rejection of a FAC involves more representations, more discursive levels and more discursive entities. The cognitive effect is represented by the 'contradiction and elimination of some contextual assumptions', assumptions which can be part of a public, mental or abstract representation. In other words, one's representation of the world is improved when there is a contradiction between some new and old information (Sperber and Wilson, 1995:114). As indicated in Fig. 3, the interpretation process goes through the activation and rejection of a FAC, which is in a contradictory relation with the negative utterance and, therefore, qualified as false assumptions. The activation of FAC can be marked explicitly at the discourse level or can be left implicit for the hearer to infer it with some additional cognitive cost. On the contrary, the situation described in (b), when there is no FAC activated in the given context, indicates that it is rather a case of DN, i.e. a first-order interpretation, as discussed in section 3 .

Let's take a look at the following two examples in (22) extracted from the UK Parliament on the 6th of January 2014 and in (23) representing the intervention of a Romanian politician during a TV political debate. There are no explicit markers used in neither of them in order to indicate whether the underlined negations are descriptive or metarepresentational. To discriminate between the two possible configurations, particular attention will be paid to see whether there is a FAC activated or not:

(22) Elizabeth Truss: The hon. Lady is cherry-picking her statistics. Many studies show that costs have stabilised under this Government, and they are in line with inflation. Her colleague in the House of Lords, Baroness Hughes, admitted that she got it wrong when Labour was in power, when costs went up by $£ 1000$ a year. We have upped the amount of free child care for three and four-year-olds from 12 and a half hours a week to 15 hours a week, supporting hard-working families, but we are not making unfunded promises such as spending the bankers levy 11 times. (UK Parliament, 6th January 2014)

(23) Victor Ponta: Apreciez că domnul Vasile Marica vrea să fie imparțial și să ne înjure și pe unii și pe alții. Unu, nu suntem noi la guvernare și doi, dacă vreți pot să vă dau exemplul meu. Cât am fost ministru nu numai că n-am mărit, am avut la jumătate toate locurile și de consilieri... dar sigur, n-a ajutat asta.

Unu, nu suntem noi la guvernare

one not are $1 P L$ we in office

'Victor Ponta: I appreciate the fact that Mr. Vasile Marica wants to be impartial and to swear at us all. Firstly, we are not in office and secondly, if you want, I can give you my own example. As long as I have been minister, not only did I not raise, but I had only half of the consultants ... but, of course, this did not help.'

In both examples, negation consists in only one segment, no positive follow-up being used. As previously mentioned, the scope of negation is underspecified and representationally ambiguous. At a closer look, certain markers that guide the reader's interpretation towards the intended one can be identified. For instance, in (22), the negation is introduced by the 'contrastive but' which separates the actions mentioned before and after its use. Also, there is the possibility of inserting an explanatory comment, such as: as others do, which leads to the following assumption: there are politicians that make unfunded promises. The presence of this commentary points towards the existence of the FAC: we make unfunded promises such as spending the bankers levy 11 times. In other words, the glossing formula is represented by: $[\operatorname{Not}(\mathrm{X})]$, where $(\mathrm{X})$ is represented by: (we make unfunded promises such as spending the bankers levy 11 times).

The question that immediately comes to mind is the following: How is this FAC activated? If we compare this example with the one in (11), there are some similarities: the rejection has an anticipatory function, i.e. the FAC is activated and becomes part of the hearer's cognitive environment after encountering the negative utterance. It results that during the interpretation process the FAC is representationally used retroactively. The speaker and the politicians that belong to the 
same party are not accused of having made unfunded promises. On the contrary, there are other politicians that make unfunded promises, and by highlighting this aspect the speaker separates her group from the others. The computation behind this negative utterance is complex, leading to a conditional type of reasoning and a causal explanation: If you think that we are making unfunded accusation, it is not true. There are others who are or others are making unfunded promises and it is not our case.

On balance, there are two main types of FAC: first, the FAC can be previously used or at least hinted at in the hearer's discourse and second, it can be created retroactively by means of negation, as it was the situation in (11) and (22). Even if the two types of FAC lead to the computation of a MetNeg, there are differences given by the different status of FAC at the level of the representations used and the cognitive cost needed in the interpretation process. In the first situation, if FAC has been previously used, it means that it is part of the actual context and is used in the comprehension process as any other representation. In the second situation, FAC is presented as a contextual assumption which enriches the actual context during the computation phase. The cognitive cost is greater in this case as FAC is presented as being part of a thought which is false and at the same time attributed to either the hearer of to a different discursive entity. In other words, in the latter situation the complexity of the comprehension process is given by the anticipation of a false thought attributed to a particular discourse entity.

The same mental structure can be noticed in example (23). The glossing formula of this structure is represented by [Not (we are in office)]. Regarding the discursive entities involved in this negative structure, it can be said that the hearer is not directly involved in the computation of this structure. The structure is addressed to a different discursive entity, explicitly mentioned: Mr. Vasile Marica. In this situation the FAC is attributed to this third discursive entity, while the hearer is just an intermediary discursive entity. Moreover, the hearer is responsible for the reiteration of a previous statement that belongs to Vasile Marica. In sum, the entire discursive sequence can be interpreted as a stimulus for the speaker's answer. The rejection targets an assumption the speaker attributes to the third discursive entity according to which they, i.e. the speaker and his party, were in office. Therefore, the speaker assumes the availability of the FAC: Vasile Marica believes that we are in office, and rejects it as he considers it inappropriate, false.

In sum, MetNeg is the actualization of the metarepresentational use, always involving a second-order representation. It is exclusively computed around the rejection of a FAC, as a result of the 'contradiction and elimination of an existing assumption' cognitive effect. MetNeg consists in a rejected representation, i.e. LOR, found in the cognitive domain of the negative operator, marked by $(X)$ in the glossing formula [Not $(X)]$.

Depending on the context and background knowledge, rejection can target different aspects and may be applied to different elements. It can be used alone or it can combine with other mental operations. Thus, there are structures built either on [simple rejection], as in (15), (22), (23) or on [rejection + correction], as in (16). The negative operator together with other elements can form correlative pairs with unitary functioning, such as: [not ... corrective but], [not only ... but also], [not just]. In comparison with the cases of simple rejection, the structures that are the outcome of [rejection + correction] mental acts are complex, consisting in two representations: a rejection representation and a correction representation. In light of this characterization, the negative operator and the three correlative pairs appear to be explicit triggers of metarepresentation. The glossing formulas indicate that their predetermined mental structures are part of the schematic sentence meaning, i.e. they have a fixed, abstract character and contribute to relevance by guiding the hearer towards the intended explicit content.

Important differences appear at the level of the negative utterance followed by the corrective segment, i.e. introduced by 'corrective but', in opposition with the negative utterances used alone. The role of correction is to specify the scope and semantic domain of negation, leading the hearer towards the intended interpretation. It is said that the metalinguistic use of negation standardly occurs in rejoinders to utterances of the corresponding affirmative. The corpus investigation conducted in this paper indicates that MetNeg is a complex and heterogeneous class that also includes examples of negative utterances used alone. There are plenty of example of MetNeg [Not (X)] where there is no correction segment and the activation of a FAC is the only element that triggers the computation of the negative utterance. For instance, the phrase that Nixon uttered during a televised question and answer session with the press in $1973^{9}$ that became famous:

(24) People have got to know whether or not their President is a crook. Well, I'm not a crook. I've earned everything I've got.

is exclusively used around the FAC embedded in the following line of reasoning: if you believe that I am a crook, it is not true. A similar situation of simple rejection $[\operatorname{Not}(\mathrm{X})]$ is represented by the case of Christine O'Donnell, a Republican

\footnotetext{
${ }^{9}$ Kilpatrick, Carroll (November 18, 1973). "Nixon tells editors, 'I'm not a crook”'. The Washington Post. Retrieved July 17, 2011.
} 
candidate who ran for the 2010 U.S. Senate special election in Delaware. During the campaign, she used the following utterance:

(25) I Am Not a Witch ${ }^{10}$

which became the catchphrase of her political campaign advertisement. The example in (25) is also used only in relation to the FAC according to which people believed that she was involved in witchcraft, after an interview regarding some of her previous activities. In the first example, the FAC is mentioned by the speaker as part of an 'yes-no' question, while in the second one the speaker used the utterance as a reaction to the already existing assumption she rejects as false: they believe that I am a witch.

There are some linguistic markers that could help discriminate between a descriptive or a metarepresentational reading. For instance, the use of the negative word in capital letters indicates that 'not' is stressed and what follows after should be interpreted as [Not $(\mathrm{X})]$. A second clue is represented by the reversed order 'not that', indicating that the embedded clause is the outcome of a contradiction, and is therefore rejected on grounds of being false.

The expression and activation of FAC may occur in various forms and can be either marked explicitly or left implicit. In the first situation, which usually corresponds to cases of reported speech and thought where the rejected assumption is presented as mutually manifest, there is evidence provided for the presence, type and source of rejection. In the second situation the recovery of FAC is made by pragmatic analysis, which implies the derivation of more cognitive effects and sometimes of extra processing effort, as the hearer has to infer the source, nature and status of rejected representation. In the latter case, the rejected representation can be presented as being part of the hearer's cognitive environment in different ways: for instance, some thoughts and beliefs the hearer or the audience might have are retroactively rejected by the speaker or the speaker dismisses potential thoughts he attributes implicitly to the hearer.

On balance, in this section a general description of MetNeg has been offered based on the analysis of some authentic Romanian and English data. The mental structure and interpretation of MetNeg necessarily involves the activation and rejection of a FAC. The activation can take place either before or after encountering the negative utterance. MetNeg, either as [simple rejection] or as [rejection + correction], represents the output of the cognitive effect represented by the 'contradiction and elimination of some contextual assumptions'. The contradiction and elimination occur as a result of the contradictory relation between FAC and NEG, as Fig. 2 shows. The existing assumption represents old information, which can be presented in different ways: (i) it can be considered true by the hearer, (ii) the speaker thinks it is part of the hearer's cognitive environment, (iii) he assumes it may become part of the hearer's cognitive environment at some point.

\section{2. $D N$}

In the previous section it has been emphasized that the activation and rejection of a FAC leads exclusively to a metarepresentational reading. Let's take a look at the following example, where no FAC seems to be activated:

(26) Stelian Tănase: Ce au zis ceilalți ministeriabili, care nu s-au văzut pe listă? Că acolo sunt mulți oameni cu pretenții, care ar putea să aibe...

care nu s- au văzut pe listă

those not pron refl saw $3 P L$ on list

Stelian Tănase: what did the other ministers say, those who did not see (their names) on the list? Because there are many people with pretensions, who might have...

The negative structure represents an attributive clause embedded in a question which indicates that the assumption conveyed by the negative content is presented as being mutually manifest, while a different informational content is being questioned and negotiated. By means of negation, the existence of two realities is implied. The second component of the pair is not explicitly expressed but it can be easily recovered from the context: those who saw their names on the lists. The dichotomy between other ministers indicating those who did not see themselves on the lists and these ministers indicating those who have seen themselves on the lists is created, which equally contribute to the overall meaning of the utterance. Concretely, the accent is placed on the answers offered by those who were not on the list. Therefore, the role of such a negative structure is informative, providing the hearer and the audience with new information which is meant to strengthen the information displayed in the previous segment.

\footnotetext{
10 http://knowyourmeme.com/memes/i-am-not-a-witch.
} 


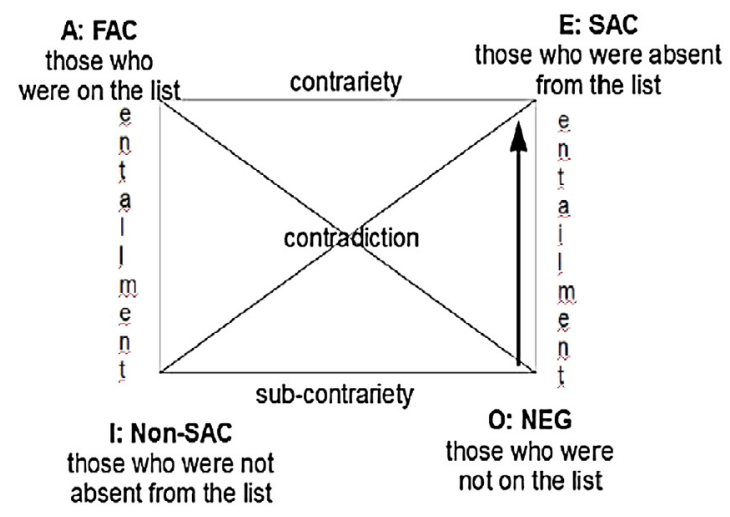

Fig. 5. The interpretation process for DN.

Taking a closer look at the negative structure those who did not see themselves on the lists, it can be noticed that it is similar with those who were not (present) on the lists and with those who were absent from the lists. This means that in this situation the negative clause has a SAC available, as indicated in Fig. 5.

If one tries to replace the NEG with the available SAC, the meaning of the utterance does not seem to change. It appears that the interpretation process in this situation does not go through representing the FAC (which is false by default), but it reaches the SAC: those who were absent from the list. Even if, according to the logical predictions, SAC always entails NEG, the interpretation goes directly from NEG to SAC, without activating any FAC, as indicated by the direction of the arrow in the above-mentioned figure. Therefore, there is a shift from the NEG to SAC in the mental structure and interpretation process of $\mathrm{DN}$. In other words, the shift occurs from the predicate denial to the predicateterm denial, i.e. from $\mathrm{O}$ to $\mathrm{E}$, which implies that there is a shift from a wide-scope sentential negation to a narrow-scope constituent negation, from a contradictory $\mathrm{O}$ to a contrary $\mathrm{E}$. This shift corresponds to the principle of MaxContrary (Horn, 2014), according to which the negation of a contradictory (wide-scope negation) $\neg p$ to strengthen a contrary of $p$ in different contexts. In sum, DN can be explained as the $O>E$ drift, i.e. the pragmatic strengthening of a contradictory in a contrary in natural language. It is not a case of contradicting and eliminating some existing assumptions, but rather a case of asserting a negative content, ${ }^{11}$ defined in terms of absence or non-existence of some properties, entities or state of affairs.

A similar situation can be noticed in the English data, as well:

(27) The Bill puts in place a recall mechanism for MPs which is transparent, robust and fair. It strikes a fair balance between holding to account those who do not maintain certain standards of conduct, while giving MPs the freedom to do their job and make difficult decisions where necessary.

(28) The St Anne's flag is an example of our work with the Flag institute to help local communities to produce their own local flag where they do not have an historic flag. St Anne's on the Sea town council worked with its local civic society and the Flag institute on the design of its flag which was first raised in the town last year. We are encouraging other areas across the country to come together and design their own flags to celebrate their local identity and community spirit.

Similarly to examples (10) and (26), the idea of two groups is created in (27): those who maintain and those who do not maintain certain standards or those who obey and those who disobey certain standards. If we replace the negation with the most available SAC, there does not seem to be any significant changes in the meaning interpretation path: the FAC is by default considered false, i.e. the hearer does not go through the FAC to reach the intended interpretation, instead he goes straight to the available SAC in the given context.

In (28) the idea of bipolar groups is maintained: there are communities that have historic flags and communities that do not. In terms of SAC, the negative clause could be replaced by where they lack a historic flag, pointing to a situation where the flags are non-existent. One direct implication would be that the negative content is not determined entirely by the

\footnotetext{
${ }^{11}$ Even if the notion of negative content may be controversial, there are views defending the idea of a 'negative state of affairs' and of nonexistence (cf. Crane (2012), Foolen (1991), Horn (1989, chapter 1) and see Reicher (2014)) for literature overviews. Further proof comes from the psycholinguistic literature which points out that people first simulate negated state of affairs Kaup et al. (2007).
} 
action of the negator. Instead, it can be determined by other elements as well, especially by lexical counterparts, as in the case of the previously mentioned symmetrical contrary pairs like: not to be present vs. to be absent. From this perspective, it can be inferred that the negative content is rather a conceptual notion that opposes the presence of a property to the absence of it or the achievement of an action to its cessation. It can be interpreted like a negative assertion, where the speaker's intention is to assert the absence of some properties of the mentioned entities. The properties of assertion tally with the descriptive use, as it involves "a descriptive relation between the speaker's thought and a state of affairs in the world" (Sperber and Wilson, 1995:231).

If we take a comparative look at examples (10), (26), (27) and (28), the following similarities can be noticed. First, the idea of bipolarity and dichotomous pairs is created those who and those who do not maintain certain standards of conduct, communities where they have and communities where they do not have an historic flag. Second, syntactically speaking, all instances identified as DN are embedded clauses: for instance, attributive patterns like those who, temporal clauses like when you were not the president or place clauses like where they do not have an historic flag. One possible explanation for this would be that the FAC is blocked by embedded contexts, like where, those who, when, as it is used to characterized the other groups, i.e. two descriptions are available, a positive and a negative one, of the same object or entity. $^{12}$

On the contrary, the MetNeg [Not $(X)]$ usually represent either the main clause or if they are part of an embedded clause they are introduced by I recognise that, the Government considers that, which play an important role in triggering the metarepresentational reading, like in the following examples:

(29) I recognise that LSER has not always met the expectations of passengers and so this agreement contains rigorous satisfaction and performance targets, with financial penalties if they are not met.

(30) It is crucial that the new system beds in quickly, and that practitioners, from authorities to developers, recognise the weight that Government give to the approach we are setting out. We are confident that the benefits of this new simplified system will be recognised widely-especially given the flexibility this new approach provides to support the delivery of high quality housing. Nevertheless, if in the light of experience of applying the system the Government consider that it is not being applied as intended by planning authorities, then legislation will be considered.

The expectation created in (29) is the following: it was expected of them to meet the expectations of passengers, which is activated by using the verb recognise. The glossing formula of this utterance is: I recognise that [Not $(X)]$. The FAC is activated retroactively, after the encounter of the negative utterance. The insertion of a meta-comment highlights where the contradiction between the FAC and NEG occurs: as it was supposed to (i.e. to meet the expectations of passengers).

In the second example the phrase as intended plays a disambiguating role, leading the interpretation towards a metarepresentational reading, with the possibility of inserting the following explanatory comment: the legislation is supposed to be applied, but it is not the case. Similarly to the previous situation, the FAC has the form of an expectation, confirmed by linguistic elements like I recognise and as intended, respectively.

A slightly different discursive pattern of DN can also be noticed in the available corpora:

(31) Victor Ponta: Bună seara, domnule Robert Turcescu!

Robert Turcescu: Ce mai faceți, domnule Victor Ponta?

Victor Ponta: Mă uitam cum trece timpul. Dumneavoastră erați la altă televiziune, la Realitatea TV, eu nu eram președinte de partid. Dar oricum, aveam părul mai negru.

eu nu eram președinte de partid

I not was 1 SG president prep AC. party

'Victor Ponta: Good evening, Mr. Turcescu!

Robert Turcescu: How are you, Mr. Ponta?

Victor Ponta: I was thinking of how time passes. You were at a different TV station, at Realitatea TV, I was not the party president. But anyway, I had darker hair.'

\footnotetext{
12 Following the research direction suggested in Blochowiak (2009) and Moeschler (2006, 2013) concerning the negative descriptions of events, according to which the events under negation become states, it can be noticed that there are only states in all the DN examples. The present article does not provide enough data in order to pursue this line of research, as there does not seem to be any change in the aspectual class of DN. Nevertheless, it is a topic worth investigating in future research.
} 
The negative structure does not appear to be an embedded clause, it is rather part of a paragraph with a descriptive function. ${ }^{13}$ The reference to a past moment is set and then both positive and negative descriptions (you were at a different $T V$ station; I was not the party president, respectively) are offered to characterise it. This negative occurrence is similar to example (10), where the SAC: I had a different function in the party is activated.

Another similarity is found at the level of how the cognitive effect is derived. As regards DN, contrary to MetNeg, the cognitive effect is represented by 'strengthening some existing assumptions', which leads to a special case of 'contextual implication'. According to Relevance Theory, a contextual implication is a sub-type of synthetic implication, which means that it cannot be demonstratively inferred from any one of its premises (Sperber and Wilson, 1995:112). There are three types of contextual strengthening, as follows:

i. 'dependent': the strength of the conclusion depends not only on the added premises $P$ but also on the context $C$,

ii. 'independent': when a single conclusion is independently implied by two different sets of premises, and

iii. 'retroactive': the assumptions used in a contextualisation may be strengthened by the fact that the contextualisation has had some expected result.

The discussed examples appear to be cases of dependent strengthening, as a result of a contextual implication $Q$ which is demonstratively inferred from $P$ by assuming $C$. To illustrate, if we take, for instance, the case of example (28), we obtain the following material implication If $P$ then $Q$ :

(32) If the Flag Institute helps St Anne, then St Anne does not have an historic flag

The Flag Institute helped St Anne

Then St Anne did not have an historic flag.

Nevertheless, further investigation of DN is required in order to answer a series of questions. The first set of questions concerns the activation and use of SAC which is said to be part of the negative content and characterized as 'lacking' some properties in the given context in opposition with the other group. Concretely, future research will focus on the manner in which one SAC is selected and activated out of many options in a given context.

Differences are to be found in terms of cognitive behaviours at the level of both contrary and contradictory expressions under negation (cf. Kaup et al., 2006; Paradis and Willners, 2006). In our context, those who do not maintain does not have immediately a SAC available, as it is the case with classical binary pairs. A research question worth investigating is represented by the lexical unavailability of SAC, i.e. some properties that are not present in the lexicon.

The second set of questions regards the notion of negative content. The main features of negative content as well as the mechanisms that allow its actualisation require further analysis in the future. In this paper a sample analysis of DN has been provided with an emphasis placed on its logical and pragmatic features but an extensive corpus analysis is required in order to identify and account for more, of not all, instances of DN.

In sum, in this section particular attention has been paid to the characterization of DN. Contrary to the mental structure of MetNeg, no FAC is activated nor required in the computation and interpretation of DN. Instead a SAC is always available, regardless if it is lexicalized or not. Among its main features, the following can be mentioned: DN represents the pragmatic strengthening of a contradictory in a contrary, representing the $\mathrm{O}>\mathrm{E}$ drift. Consequently, it corresponds to the semantics of a narrow-scope constituent negation: $\exists x \neg B(x)$, as the description of a negative content, defined as the absence of non-existence of some properties, entities or state of affairs in a given context. The negative content is interpreted as encoding conceptual meaning and can be expressed by negation but also by the available lexical counterparts. Further research will concentrate on any processing differences that may occur between SAC and NEG.

The interpretation suggested for DN and MetNeg in this paper is different with regard to the direction developed in the literature, indicated in section 2. For instance, the perspective defended in this article presents DN in a new light. In the literature, an utterance like the following:

We didn't see the hippopotamuses. We saw the rhinoceroses.

is considered an instance of DN, where the first clause is considered to be "descriptive of some aspect of the world" (Carston, 1996:309), i.e. truth-conditional, implying a rejection of the truth-conditional semantic content. In the spirit of the analysis developed here, such a structure involves metarepresentation, i.e. there are more levels implied: HOR and LOR.

\footnotetext{
${ }^{13}$ Descriptive function is defined as: "to tell or depict in written or spoken words; give an account, to indicate; to denote" (http://dictionary. reference.com/browse/describe) or "a detailed account of the certain or salient aspects, characteristics, or features of a subject matter or something seen, heard, or otherwise experienced or known" (http://www.businessdictionary.com/definition/description.html).
} 
The negative segment is used as a reaction to a previous FAC, expressed explicitly, inferred or meant to be inferred by the addressee in the given context: we saw the hippopotamuses, which leads to a metarepresentational reading and not to a descriptive one, as described in section 3.

If we adopted this perspective, DN would turn into a metarepresentational $\mathrm{DN},{ }^{14}$ which would lead to the erasure of the descriptive use when computing a negative utterance. Nevertheless, an account of DN with metarepresentational properties is also offered in Moeschler (2013). The mismatch between DN in the literature and the approach to DN adopted here appears to come from a different use of notion 'descriptive'. If in the present paper 'descriptive' refers to the descriptive use, in Moeschler (2013) descriptive negation can be equated to 'ordinary negationn or 'downward negation', whose truth-functional properties of entailment are always preserved. For instance, the following utterance (taken from Moeschler, 2013:78), which is similar with example (4):

(34) Abi is not beautiful; she is ordinary.

is interpreted as ordinary or descriptive negation having the following properties: is truth-functional, scopes over a proposition and is entailed by the corrective segment, as follows:

\section{(35) Abi is beautiful $\rightarrow$ Abi is not ugly.}

In other words, this type of negative utterance is labelled descriptive based on the downward orientation given by its semantic properties. On the contrary, the account provided here treats these types of utterances as the output of the metarepresentational use (as previously discussed), together with the upward negation in (3), the 'neutral' negation in (5) and the simple rejection in (2).

There are two direct implications of presenting the descriptive use and the metarepresentational use as mutually exclusive. First, DN consists in only one segment, i.e. the negative one, pointing towards a descriptive use. Second, a corrective follow-up, as in (33), always indicates a metarepresentational structure, which can have different discourse functions. Thus, (33) is rather a case of MetNeg of truth-based content than a DN. This approach defends the monoguist view, according to which there are no semantic specialization for the different meanings of negation; instead the pragmatic processes enable the relevant mental structure and interpretation.

In conclusion, based on the analysis of the Romanian and English data, it results that DN is a first-order representation while MetNeg is the actualization of the metarepresentational use. The mental structure of each of them is fixed, i.e. DN and MetNeg undergo specific processes of meaning computation and interpretation. They represent the output of different mental actions and different cognitive effects: DN is the output of the cognitive effect represented by the strengthening of some contextual implications, while MetNeg is a second-order interpretation, always the output of the cognitive effect of the contradiction and elimination of some contextual assumptions. In the latter situation, the effect of the negative operator not on the material found in its scope is to reject and eliminate an existing set of assumptions for different reasons. In the former it is to describe a negative content.

\section{Conclusions}

This paper aims at describing the cognitive and discursive individuality of descriptive negation and metarepresentational negation from a relevance-theoretic perspective. In the analysis of negative utterances, a dissociation between the mental structure of negation, i.e. the triggered inferences and yielded cognitive effects, and its discursive contribution, i.e. the functions and discursive roles, has been put forward. The approach is based on the premise that DN and MetNeg have predetermined mental structures, each of them emphasizing particular contexts of interpretation.

After setting the theoretical framework represented by the dichotomy between 'descriptive use vs. metarepresentation', according to which they are mutually exclusive, i.e. descriptive use is always a first-order interpretation while metarepresentation is a second-order interpretation, particular attention has been paid to the constitutive elements of a negative utterances and to the relations among them. The main criteria is represented by the different relations displayed by the formal affirmative correspondent and the semantic affirmative correspondent in computing and interpreting a negative utterance. When a FAC is activated, the negation represents the result of an action of rejection. Therefore, MetNeg is the actualization of metarepresentational use, constitutes the output of the cognitive effect represented by 'the

\footnotetext{
${ }^{14}$ DN is defined as an instance of non-echoic metarepresentational use (Carston, 1999:380) but it characterizes an utterance like: John is a bachelor entails John is unmarried, which is described as being non-echoic and representing a proposition or a concept, corresponding to the metaconceptual variety of non-echoic type of metarepresentation.
} 
contradiction and elimination of an existing assumption' and is computed as 'the rejection of a representation'. In contrast, $D N$ is the 'description of a negative content', always a first-order representation, being the output of the 'strengthening of some contextual implications' cognitive effect. In conclusion, DN and MetNeg represent two types of negative structures that have distinct mental structures, i.e. they represent the output of different mental actions and different cognitive effects, and their interpretations are the result of the interplay between logical, semantic and pragmatic features.

SAC plays an important role in the computation and interpretation of negative utterances. In light of the discussion developed in this paper, its complexity is captured in the following lines:

i. when the negative segment is used alone and SAC could replace it, it is a situation of DN,

ii. when the negative segment is followed by a SAC, there are two situations:

- followed by a correction segment introduced by corrective but, which leads to a downward type, an upward type or a neutral type of MetNeg

- followed by an explanation segment introduced by because, which also leads to MetNeg

iii. when the SAC is used on the first position, followed by negation, it also leads to MetNeg ${ }^{15}$

This paper emphasizes the impact of human reasoning on the interpretation of natural language with direct reference to negation, using as primary methods logical, pragmatic and corpus-based analysis. It contributes to the debate between semantics and pragmatics, on the one hand, by bringing into discussion different properties of negation that modulate meaning computation and interpretation, and to the interface between logic and cognition, on the other, by discussing the place logic occupies in the context of the architecture of the human mind. It also emphasizes the role metarepresentation plays in meaning construction and also explains how the speaker takes the perspective of the listener in order to explain and understand what it has been conveyed. In comparison with previous studies, this paper provides a corpus analysis of authentic Romanian and English data and accounts both for the cases when negation is used alone or followed by a follow-up affirmative segment. Regarding the former situation, the scope of negation becomes specified in relation with the contextually available semantic affirmative correspondent. Furthermore, DN is redefined in the suggested theoretical framework and, consequently, limited to a class of negative structures that consist in only one clause and represent a firstorder interpretation. This delimitation between DN and MetNeg can also account for different types of encoded information, various displays in terms of information structure and the existence of different stages in the acquisition of negation.

\section{Acknowledgments}

I would like to thank the anonymous reviewers for their comments. I am very grateful to Jacques Moeschler, Pierre Larrivée, Karoliina Lohiniva and Joanna Blochowiak for reading drafts of this paper and making many helpful and valuable suggestions. The remaining mistakes are my responsibility.

\section{References}

Albu, E., 2012a. The Pragmatics of Negative Structures in Political Discourse. A Relevance Theoretic Approach. PhD dissertation. University of Bucharest manuscript.

Albu, E., 2012b. Descriptive and interpretive use in the analysis of negation. In: Zafiu, R., Stefanescu, A. (Eds.), Romanian Language: Current Paths in Linguistic Research. Bucharest University Press, pp. 187-202.

Albu, E., 2012c. Metarepresentational Negation [(X’) not (X)]. In: lonescu-Ruxăndoiu, L., Roibu, M. (Eds.), Results and Perspectives in Romanian Linguistic Research. European Institute, Iasi, pp. 9-35.

Blochowiak, 2009. La relation causale, ses relata et la négation. Nouveaux cahiers de linguistique française 29, $153-175$.

Borschev, et al., 2005. Sentential and constituent negation in Russian BE-sentences revisited. In: Filip, H., Franks, S.L., Lavine, J., TassevaKurktchieva, M. (Eds.), Formal Approaches to Slavic Linguistics: The Princeton Meeting 2005 (FASL 14). Michigan Slavic Publications, Ann Arbor.

Carston, R., 1996. Metalinguistic negation and echoic use. J. Pragmat. 25 (3), 309-330.

Carston, R., 1999. Negation and metarepresentation: a response to Noel Burton-Roberts. J. Linguist. 35 (02), 365-389.

Carston, R., 2002. Thoughts and Utterances: The Pragmatics of Explicit Communication. Blackwell Publisher.

Crane, T., 2012. What is the problem of non-existence? Philosophia 40, 417-434.

Ducrot, O., 1972. Dire et ne pas dire. Principes de sémantique linguistique. Hermann, Paris.

Ducrot, O., 1984. Le Dire et Le Dit. Les éditions de Minuit, Paris.

Foolen, A., 1991. Metalinguistic negation and pragmatic ambiguity: some comments on a proposal by Laurence Horn. Pragmatics 1, 217-237. Grice, P., 1989. Studies in the Way of Words. Harvard University Press, Cambridge, MA.

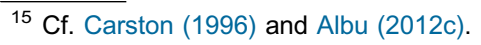


Horn, L., 1985. Metalinguistic negation and pragmatic ambiguity. Language 61 (1), 121-174.

Horn, L., 1989/2001 A Natural History of Negation. University of Chicago Press.

Horn, L., 2014. The singular square: contrariety and double negation from Aristotle to Homer. In: Blochowiak, J., Grisot, C., Durrlemann-Tame, S., Laenzlinger, C. (Eds.), Festschrit à l'occasion du 60e anniversaire de Jacques Moeschler. http://www.unige.ch/lettres/linguistique/moeschler/ Festschrift/Festschrift.php

Horn, L., Wansing, H., 2015. Negation. In: Zalta, E.N. (Ed.), The Stanford Encyclopedia of Philosophy.

Jespersen, O., 1917. Negation in English and Other Languages. Eijnar Munskgaard, Copenhagen.

Kaup, B., Ludtke, L., Zwaan, R., 2006. Processing negated sentences with contradictory predicates: is a door that is not open mentally closed? J. Pragmat. 38, 1033-1050.

Kaup, B., Yaxley, R.H., Madden, C.J., Zwaan, R.A., Lüdtke, J., 2007. Experiential simulation of negated text information. Q. J. Exp. Psychol. 60, 976-990.

Klima, E., 1964. Negation in English. In: Fodor, J., Katz, J. (Eds.), The Structure of Language. Prentice-Hall, Englewood Cliffs, pp. $246-323$.

McCawley, J., 1995. Jespersen's 1917 monograph on negation. WORD 46 (1), 29-39. http://dx.doi.org/10.1080/00437956.1995.11435936

Moeschler, J., 1993. Une, deux ou trois négations? Lang. Fr. 94, 8-25.

Moeschler, J., 1997. La négation comme expression procédurale. In: Forget, Hirschbühler, Martineau, Rivero, (Eds.), Negation and Polarity. Syntax and Semantics. John Benjamins, Amsterdam, pp. 231-249.

Moeschler, J., 2006. Négation, polarité, asymétrie et événements. Langages 162, 90-106.

Moeschler, J., 2010. Negation, scope and the descriptive/metalinguistic distinction. Gen. Gramm. Geneva 6, 29-48.

Moeschler, J., 2013. How 'Logical' are logical words? Negation and its descriptive vs. metalinguistic uses. In: Taboada, M., Trnavac, R. (Eds.), Nonveridicality, Evaluation and Coherence Relations. Brill, Leiden, pp. 76-110.

Noh, E., 2000. Metarepresentation. A Relevance-Theory Approach. John Benjamins.

Paradis, Willners, 2006. Antonymy and negation-the boundedness hypothesis. J. Pragmat. 38, 1051-1080.

Reicher, M., 2014. Nonexistent objects. In: Zalta, E.N. (Ed.), Stanford Encyclopedia of Philosophy (Winter 2014 Edition). http://plato.stanford.edu/ archives/win2014/entries/nonexistent-objects/

Russel, 1905. On denoting. Mind 14, 479-493.

Sperber, D., 2000. Metarepresentations: A Multidisciplinary Perspective. Oxford University Press, Oxford.

Sperber, D., Wilson, D., 1995. Relevance: Communication and Cognition. Wiley-Blackwell.

Tettamanti, et al., 2008. Negation in the brain: modulating action representations. Neuroimage 43, 358-367.

Wilson, D., 2000. Metarepresentation in linguistic communication. In: Sperber, D. (Ed.), Metarepresentations: A Multidisciplinary Perspective. Oxford University Press, Oxford, pp. 411-448.

Wilson, D., Sperber, D., 1988. Representation and relevance. In: Kempson, R. (Ed.), Mental Representations: The Interface between Language and Reality. Cambridge University Press, Cambridge, pp. 133-153.

Wilson, D., Sperber, D., 1992. On verbal irony. Lingua 87, 53-76.

Wilson, D., Sperber, D., 2002. Relevance theory. UCL Work. Pap. Linguist. 14, 249-287. 